\title{
Synthesis and application of multiple rods gold-zinc oxide nanostructures in the photocatalytic degradation of methyl orange
}

\author{
M. Arab Chamjangali • G. Bagherian • \\ B. Bahramian • B. Fahimi Rad
}

Received: 23 December 2012/Revised: 3 July 2014/Accepted: 18 August 2014/Published online: 23 September 2014

(C) Islamic Azad University (IAU) 2014

\begin{abstract}
Zinc oxide and gold-zinc oxide $(\mathrm{Au}-\mathrm{ZnO})$ nanostructures with multiple rods (multipods) morphology were successfully prepared. $\mathrm{Au}-\mathrm{ZnO}$ nanostructures were synthesized via a simple precipitation route method in the presence of oligoaniline-coated gold nanoparticles. The $\mathrm{Au}-\mathrm{ZnO}$ catalyst obtained was applied for the degradation of methyl orange in an aqueous solution under UV irradiation. Effects of the operational parameters such as the solution $\mathrm{pH}$, amount of photocatalyst, and dye concentration on the photocatalytic degradation and decolorization of methyl orange were studied. Detailed studies including kinetic study and regeneration of catalyst were carried out on the optimal conditions for the photodegradation of methyl orange by $\mathrm{Au}-\mathrm{ZnO}$ multipods in aqueous solution. Effect of foreign species on the photodegradation of methyl orange was also studied. An enhancement of the photocatalytic activities for photodegradation of methyl orange was observed when the gold nanoparticles were loaded on the zinc oxide multipods. The proposed catalyst was applied for the degradation of methyl orange in synthetic wastewater samples with satisfactory results.
\end{abstract}

Keywords Photocatalyst · Photodegradation . Decolorization · Gold-zinc oxide · Multipods

M. Arab Chamjangali $(\bowtie) \cdot$ G. Bagherian · B. Bahramian · B. Fahimi Rad

College of Chemistry, Shahrood University of Technology,

P.O. Box 36155-316, Shahrood, Iran

e-mail: marab@shahroodut.ac.ir

\section{Introduction}

Wastewaters contaminated with dyes remained from the textile, paper, and other industries are a source of environmental problems, especially in the third world countries. Synthetic dyes with wide variety of chemical structures and compositions of inorganic and organic compounds are one of the main groups of pollutants in wastewater (Divya et al. 2013; Robinson et al. 2001).A large amount of synthetic dyes is widely consumed in the textile industry for dyeing processes, and about $50 \%$ of these are azo dyes (Hammami et al. 2008). The chemical structures of these compounds have one or more azo groups, which are responsible for the dye color, and functional groups such as $-\mathrm{NH} 2,-\mathrm{OH},-\mathrm{CH} 3$, and $-\mathrm{SO} 3$ for the fixation of these dyes to fibers (Melgoza et al. 2009). Most azo dyes are considered to be basically nondegradable, and common degradation processes such as physicochemical treatment, active sludge, and oxidative techniques are not able to completely remove azo dyes from the contaminated wastewaters (Melgoza et al. 2009). Therefore, development of an efficient process is required to remove synthetic dyes from aqueous effluents.

The photo-assisted catalytic decomposition of organic pollutants, employing semiconductors as photocatalysts, has been a promising method for the degradation of pollutants in wastewater. Among the semiconductors, titanium oxide $\left(\mathrm{TiO}_{2}\right)$ and zinc oxide $(\mathrm{ZnO})$ are the most promising photocatalyst materials for the photo-assisted catalytic decomposition of organic contaminants. Both materials exhibit very similar band gaps $\left(\mathrm{ZnO}, 3.37 \mathrm{eV} ; \mathrm{TiO}_{2}\right.$, $3.2 \mathrm{eV}$ ) and conduction band edge positions (Wang et al. 2008). Although $\mathrm{TiO}_{2}$ is widely employed as a photocatalyst, $\mathrm{ZnO}$ is a low-cost alternative to $\mathrm{TiO}_{2}$ (Pirkanniemi and Sillanpää 2002; Hazrati et al. 2014). Higher 
photocatalytic efficiencies of $\mathrm{ZnO}$ have also been reported especially for the degradation of organics in aqueous solutions (Akyol et al. 2004; Kavitha et al. 2007; Daneshvar et al. 2004). Up to now, one-dimensional (1D) structures of $\mathrm{ZnO}$ such as rods (Cheng and Samulski 2004), wires (He et al. 2005), and hollow microspheres (Tao et al. 2008) have stimulated intensive research interest owing to their various applications. $\mathrm{Li}$ and Haneda (2003) have found that the morphology of $\mathrm{ZnO}$ powder has a considerable effect on its photocatalytic activity. Thus, some recent efforts have focused on the preparation of $\mathrm{ZnO}$ nanostructure material with different morphologies by the integration of 1D structure building blocks into 2D- and 3D-ordered super structures. Reports on the synthesis of various structures of $\mathrm{ZnO}$ have increased rapidly, including tower-like (Wang et al. 2004), dumbbell-like (Sun et al. 2009), nut-like (Zheng et al. 2010), and flower-like (Liu et al. 2006; Xie et al. 2011).

It is well known that the initiation step in the photocatalytic process consists of the generation of electron-hole pairs upon irradiation of the material with a photon having energy at least equal to that for the band gap of the photocatalyst. The electron-hole pairs formed can participate in the degradation reaction of dyes. Single-component semiconductor nanostructures exhibit relatively poor photocatalytic activity because the photo-generated electronhole pairs are simply recombined prior to the superoxide activation step (Szabó-Bárdos et al. 2003). Electron-hole recombination can be minimized by using metal on a semiconductor which metal acts as a sink for the electron and decrease recombination (Pawinrat et al. 2009). Among the different elements used for metal-semiconductor composite preparation, noble metals have been found to be more favorable for the development of semiconductors for catalytic applications (Subramanian et al. 2003; Wu and Tseng 2006; Height et al. 2006; Liqiang et al. 2006; Li and Li 2002). Among the noble metallic nanoparticles (NPs), gold nanoparticles (Au-NPs) have a greater potential to modify $\mathrm{ZnO}$ for improving its photocatalytic activity. Many developments have been achieved in this research field including synthesis of gold-zinc oxide ( $\mathrm{Au}-\mathrm{ZnO})$ nanowires (Joshi et al. 2009) or nanorods (Sun et al. 2011), but up to the present time, there is no report dealing with the photocatalytic performance of $\mathrm{Au}-\mathrm{ZnO}$ multipods.

In this work, $\mathrm{ZnO}$ and $\mathrm{Au}-\mathrm{ZnO}$ nanostructures with multiple rods (multipods) morphology were successfully synthesized. The photodegradation of methyl orange (MO) using $\mathrm{ZnO}$ and $\mathrm{ZnO}-\mathrm{Au}$ multipods photocatalysts was investigated. Detailed studies were carried out on the optimal conditions for the photodegradation of $\mathrm{MO}$ by $\mathrm{Au}-$ $\mathrm{ZnO}$ multipods in aqueous solution. The research was conducted at Shahrood University of Technology, Iran, and was completed in September 2012.

\section{Materials and methods}

Chemicals

All chemicals including zinc acetate dihydrate, sodium hydroxide, polyvinyl pyrrolidone (PVP), tetrachloroauric acid trihydrate, and citric acid were purchased from Aldrich or Merck and used as received without further purification. Aniline was purchased from Sigma-Aldrich and distilled twice under reduced pressure before use. The water used throughout this work was ultrapure, produced by a Milli-Q system.

Preparation of $\mathrm{ZnO}$ multipods

$\mathrm{ZnO}$ multipods nanostructure was synthesized according to the method proposed by Krishna et al., with some modifications (Krishnan and Pradeep 2009). A total of $25 \mathrm{~mL}$ of water was heated in a beaker at $60{ }^{\circ} \mathrm{C}$. Under constant temperature, $250 \mathrm{~mL}$ of an aqueous PVP solution (12.5 $\mathrm{mg} \mathrm{mL}^{-1}$ ) was then added. Subsequently, $25 \mathrm{~mL}$ of zinc acetate $(0.10 \mathrm{M})$ was added. The solution was homogenized by constant stirring for about $1 \mathrm{~min}$, and this was followed by the addition of $\mathrm{NaOH}(4.0 \mathrm{M})$ so as to maintain a particular $(1: 40) \mathrm{Zn}^{2+}: \mathrm{OH}^{-}$ratio. The mixed solution was stirred at $60{ }^{\circ} \mathrm{C}$ for $1 \mathrm{~h}$. After completion of the reaction, the resulting precipitate was collected by centrifugation, followed by washing with distilled water and ethanol for several times, and dried at $80{ }^{\circ} \mathrm{C}$ for $4 \mathrm{~h}$.

\section{Preparation of $\mathrm{Au}-\mathrm{ZnO}$ multipods}

For preparation of the $\mathrm{Au}-\mathrm{ZnO}$ multipods, first oligoaniline-coated gold nanoparticles (Au-NPs) solution was prepared by a known procedure described by Sajanlal et al. (2008), and this solution was then used for the preparation of $\mathrm{Au}-\mathrm{ZnO}$ multipods according to the method described for the preparation of bare $\mathrm{ZnO}$ multipods. Briefly, $25 \mathrm{mg}$ of citric acid was dissolved in $35 \mathrm{~mL}$ of water. Keeping the solution at $80{ }^{\circ} \mathrm{C}, 1 \mathrm{~mL} \mathrm{HAuCl}{ }_{4}(25 \mathrm{mM})$ was added to it. After $10 \mathrm{~min}$, when the color changed from pale yellow to pink, $100 \mu \mathrm{L}$ of distilled aniline was added followed by $500 \mu \mathrm{L}$ of $\mathrm{HAuCl}_{4}(25 \mathrm{mM})$. Heating was continued for 5 more minutes. Color of the solution changed to light pink, and a black precipitate was formed. This solution was kept at room temperature for $5 \mathrm{~h}$, centrifuged at 4,000 rpm, and the black residue obtained was discarded. The resultant 
light pink supernatant containing the oligoaniline-capped gold nanoparticles was used for further reaction. A total of $25 \mathrm{~mL}$ of this oligoaniline-capped Au-NPs solution was used instead of water in the $\mathrm{ZnO}$ multipods preparation procedure for the preparation of $\mathrm{Au}-\mathrm{ZnO}$ multipods. The product, $\mathrm{Au}-\mathrm{ZnO}$, was used for subsequent analysis.

\section{Instruments}

X-ray diffraction (XRD) patterns were obtained on a Burker AXS (Model B8-Advance) diffractometer with $\mathrm{Cu}$ $\mathrm{K} \alpha$ radiation $(\lambda=0.15418 \mathrm{~nm})$. Scanning electron microscopy (SEM) analysis was conducted using a Hitachi S-4160 electron microscope. Transmission electron microscopy (TEM) images were obtained using a Philips CM120 transmission electron microscope. Energy-dispersive X-ray spectroscopy elemental analysis of the sample was carried out using a Philips XL-30 energy-dispersive $\mathrm{X}$-ray spectroscope (EDAX). The UV-Visible spectra were recorded on a Ray Leigh UV-2610 UV-Visible spectrophotometer equipped with a pair of $1.0-\mathrm{cm}$ quartz cells. The $\mathrm{pH}$ measurements and adjustments were carried out using a Metrohm $691 \mathrm{pH}$ meter equipped with a combined glass electrode.

Procedure for photocatalytic degradation/decolorization studies

The photocatalytic experiments were carried out using a home-made photoreactor. Dimensions of the photoreactor were $120 \mathrm{~cm} \times 100 \mathrm{~cm} \times 100 \mathrm{~cm}$. A $400-W$ mercury lamp was used for the UV irradiation. The distance between the surface of the solution and the light source was about $12 \mathrm{~cm}$. In the irradiation experiment, $100 \mathrm{~mL}$ of aqueous MO with an initial concentration of $10.0 \mathrm{mg} \mathrm{L}^{-1}$ (pH 6.5) was transferred into a sample vessel. A defined mass of the photocatalyst $(10.0 \mathrm{mg})$ was added to the dye solution. Before irradiation, the suspensions containing MO and photocatalysts were continuously stirred for 20 min at dark in order to reach an adsorption-desorption equilibrium. The system was then subjected to UV light irradiation by switching on the lamp, while the suspension was stirred magnetically. At fixed time intervals, $2 \mathrm{~mL}$ of the sample was withdrawn and centrifuged to remove the catalyst particles. UV-Visible absorption spectra of the clarified solution were recorded to obtain the absorbance of $\mathrm{MO}$ at the wavelengths 464 and $272 \mathrm{~nm}$, corresponding to the maximum absorption wavelengths of MO.

\section{Results and discussion}

Characterization

XRD spectra

In order to investigate the changes in the crystal structure due to gold doping, XRD measurements were taken within the range of $2 \Theta=10-80^{\circ}$ for the $\mathrm{Au}-\mathrm{ZnO}$ photocatalyst. The XRD patterns for $\mathrm{ZnO}$ and $\mathrm{Au}-\mathrm{ZnO}$ are shown in Fig. 1. All of the diffraction peaks in the patterns could be exactly indexed as the hexagonal wurtzite $\mathrm{ZnO}$ and were well agreed with the values in the standard card (JCPDS 36-1451). It was also found that the $2 \Theta$ values at which major peaks appeared for $\mathrm{Au}-\mathrm{ZnO}$ multipods (Fig. 1b) were almost the same as those for pure $\mathrm{ZnO}$ (Fig. 1a). The amount of Au-NPs was so small that no diffraction peaks were observed for them in curve (b). The results imply that the crystalline phase for $\mathrm{ZnO}$ has not been changed by the modification of $\mathrm{ZnO}$ with Au-NPs. The average size of $\mathrm{Au}-\mathrm{ZnO}$ particles, calculated from line broadening of (101) diffraction peak using Scherer's formula, was $28 \mathrm{~nm}$, which is approximately comparable with the results obtained for the TEM analyses, and EDAX (Fig. 2) confirms that the samples primarily consisted of $\mathrm{Zn}$ and $\mathrm{Au}$.

\section{SEM and TEM images}

Figure 3 shows the typical SEM images for $\mathrm{ZnO}$ and $\mathrm{Au}-$ $\mathrm{ZnO}$ multipods, which show that $\mathrm{ZnO}$ nanorods are well aligned to form uniform multipods-like structures with

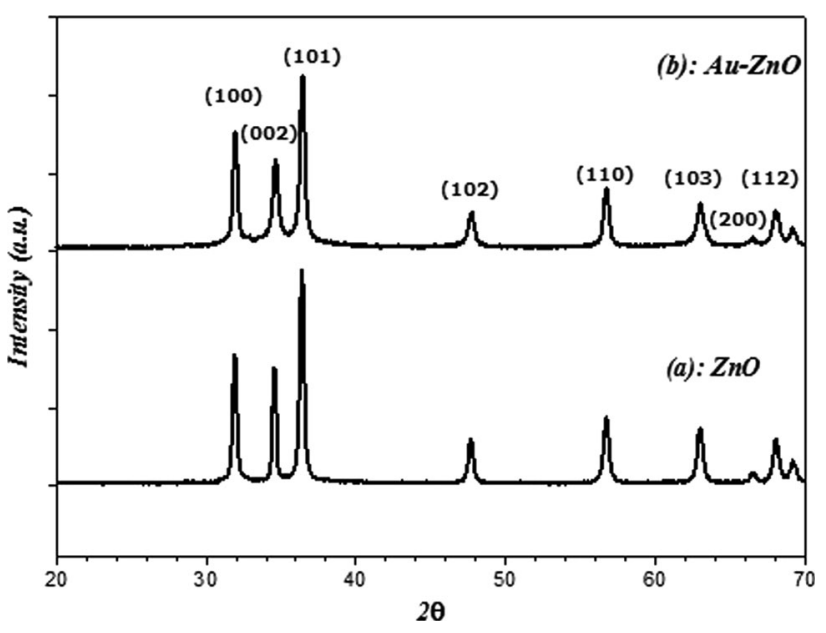

Fig. 1 XRD patterns for $\mathbf{a} \mathrm{ZnO}$ and $\mathbf{b} \mathrm{Au}-\mathrm{ZnO}$ nanostructures 


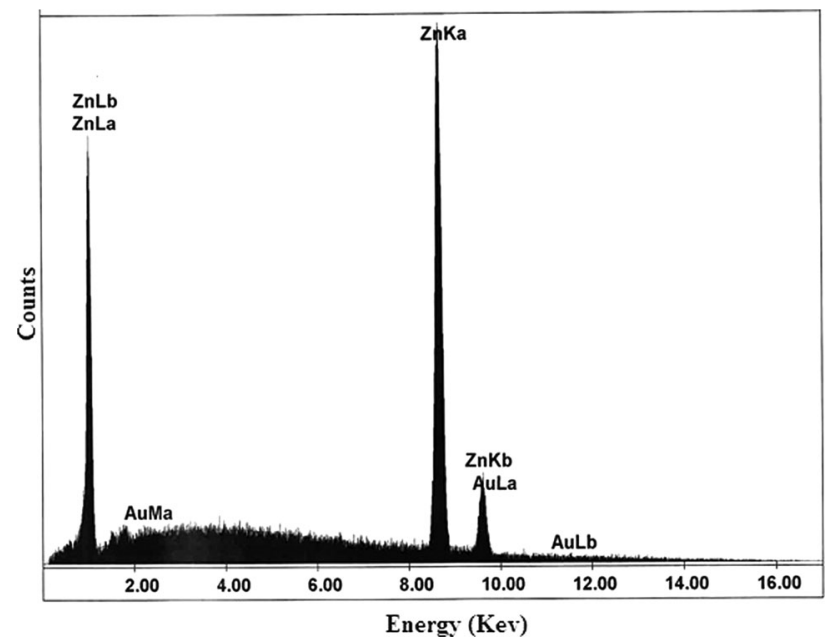

Fig. 2 EDAX spectra for $\mathrm{Au}-\mathrm{ZnO}$ with multipods morphology average size of $\sim 1-2 \mu \mathrm{m}$. By comparing the morphologies for $\mathrm{ZnO}$ (Fig. 3a, b) and $\mathrm{Au}-\mathrm{ZnO}$ (Fig. 3c, d), it is clear that the morphology of $\mathrm{ZnO}$ has not been changed by the modification of $\mathrm{ZnO}$ with $\mathrm{Au}-\mathrm{NPs}$. It can be seen from the enlarged images shown in Fig. 3b, $d$ that an individual multipods-like structure is composed of about 20-30 nanorods with a radial alignment from a center.

A further morphologic and structural characterization of the $\mathrm{Au}-\mathrm{ZnO}$ multipods was performed by TEM. A typical TEM image for one $\mathrm{ZnO}$ multipods is shown in Fig. 4a. It is clear that the morphology of $\mathrm{Au}-\mathrm{ZnO}$ is multipods and that it is in agreement with the SEM results. Figure $4 \mathrm{~b}$ displays a TEM image for several individual $\mathrm{ZnO}$ nanorods in the multipods structure. Dimensions of the nanorods under TEM observation are $\sim 50-100 \mathrm{~nm}$ in diameter and $\sim 400-500 \mathrm{~nm}$ in length with a sharp tip, which are in good agreement with the SEM results.
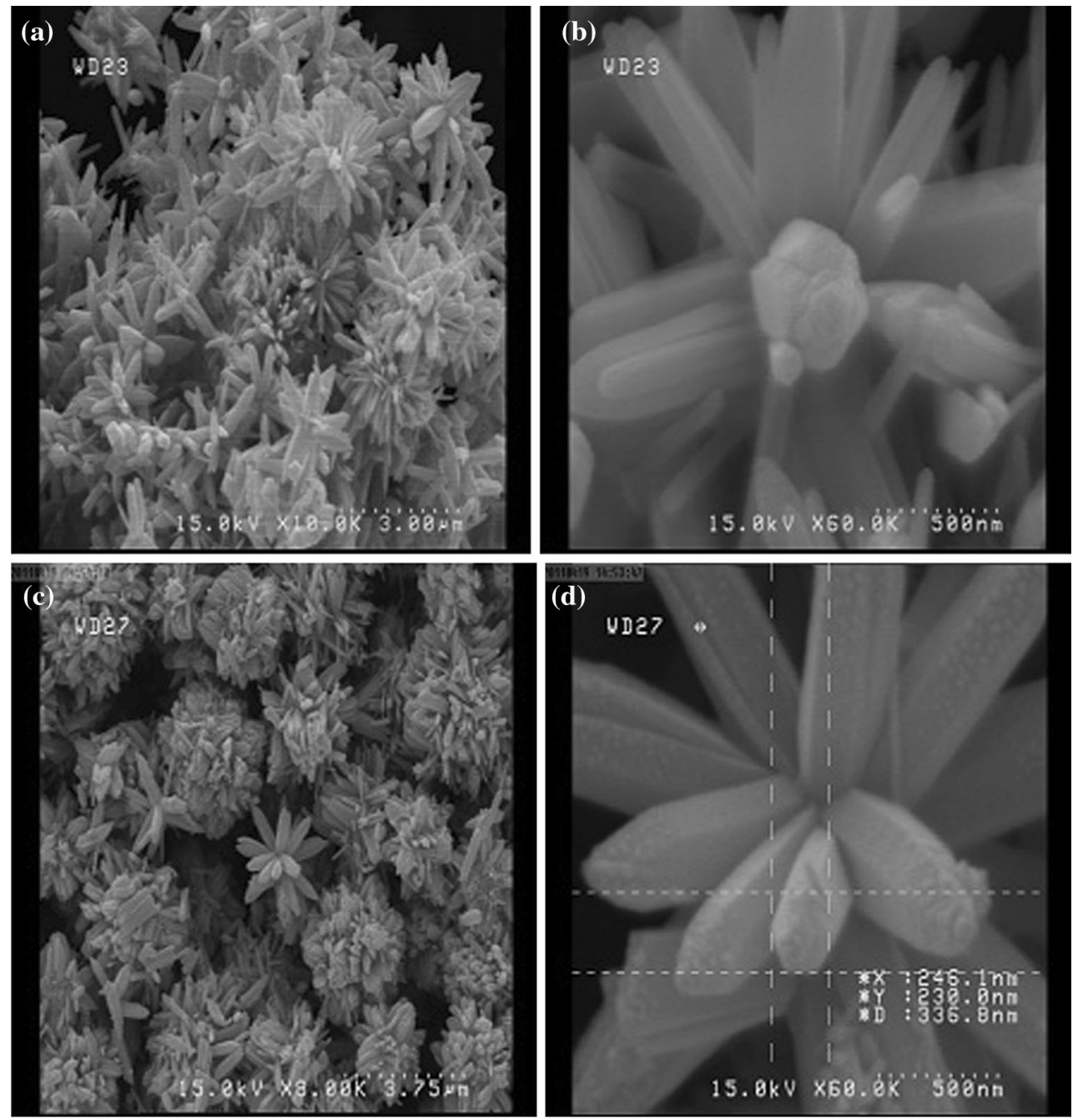

Fig. 3 SEM images of $\mathrm{ZnO}$ and $\mathrm{Au}-\mathrm{ZnO}$. a, b Are small- and large-area SEMs of the ZnO multipods; $\mathbf{c}$, $\mathbf{d}$ are small- and large-area SEMs of the $\mathrm{Au}-\mathrm{ZnO}$ multipods 
Fig. 4 TEM images of the $\mathrm{Au}-$ $\mathrm{ZnO}$ multipods. a Small area and $\mathbf{b}$ large-area images

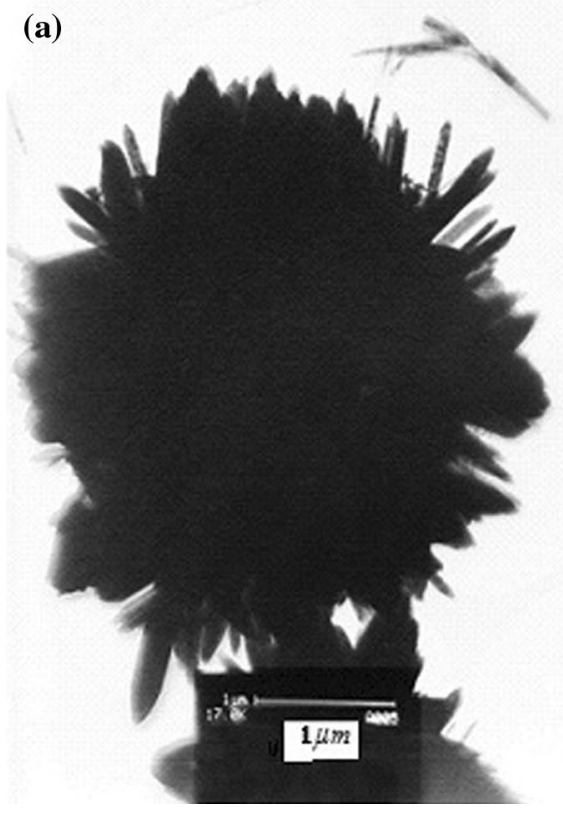

(b)

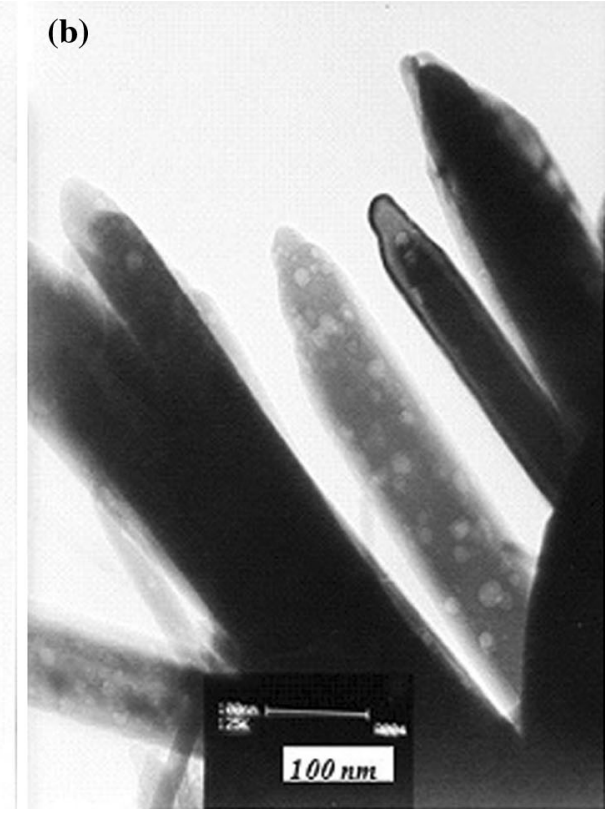

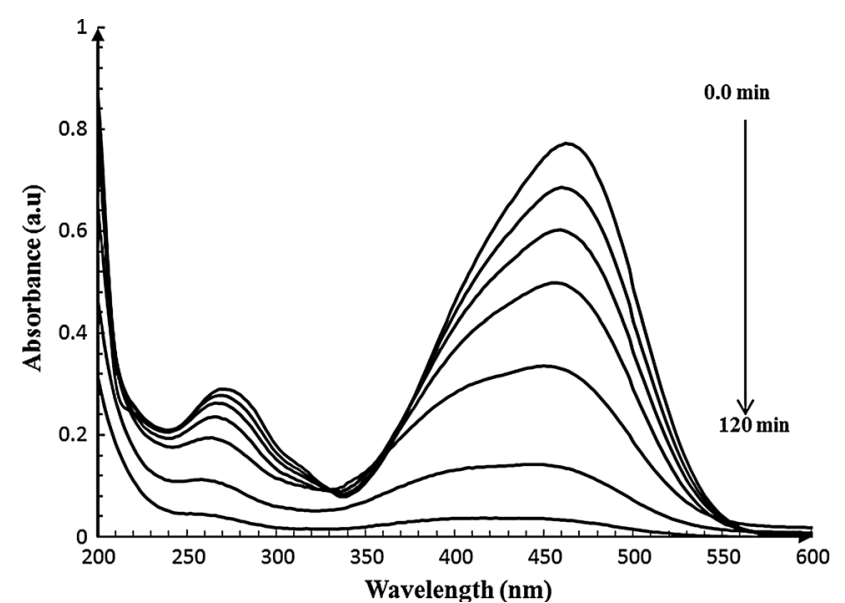

Fig. 5 UV-Visible absorbance spectra for MO solution as a function of UV light exposition time. Conditions: $100 \mathrm{~mL}$ of $\mathrm{MO}$, $10.0 \mathrm{mg} \mathrm{L}^{-1} ; \mathrm{Au}-\mathrm{ZnO}, 10.0 \mathrm{mg}$ and $\mathrm{pH} 6.5$

\section{Photocatalytic activity of $\mathrm{Au}-\mathrm{ZnO}$}

Figure 5 shows the absorption spectra for $\mathrm{MO}$ at different UV irradiation times in the presence of $\mathrm{Au}-\mathrm{ZnO}$. The changes observed in the absorbance at $464 \mathrm{~nm}$ with time are due to breaking of the azo bonds in MO, showing its decolorization. The changes observed in the absorbance at $272 \mathrm{~nm}$ with time are correlated to the changes in the concentration of organic residuals in the solution and thus the mineralization of MO. Therefore, the absorbance at $464 \mathrm{~nm}$ was used to monitor the decolorization of MO and that at $272 \mathrm{~nm}$ was used to follow the degradation of the aromatic part of the dye. Figure 6 shows the changes in absorbance of MO at $464 \mathrm{~nm}$ (decolorization) and $272 \mathrm{~nm}$ (degradation) with time under different conditions. If no UV light irradiation was used, the concentration of MO decreased a little after $20 \mathrm{~min}$ and remained unchanged even after $120 \mathrm{~min}$. This indicates that adsorption of MO on the surface of photocatalyst reaches an equilibrium condition after $20 \mathrm{~min}$. Thus, in all experiments, the suspensions containing MO and photocatalysts were continuously stirred for $20 \mathrm{~min}$ at dark in order to reach an adsorption-desorption equilibrium. According to Fig. 6, it is clear that in the absence of $\mathrm{Au}-\mathrm{ZnO}$ or $\mathrm{ZnO}$ (only UV irradiation), the degradation of $\mathrm{MO}$ does not occur, but a slight dye decolorization is observable. On the other hand, in the presence of both $\mathrm{Au}-\mathrm{ZnO}$ and UV light, nearly $100 \%$ of the dye was decolorized and degraded within $140 \mathrm{~min}$. These results signify the importance of $\mathrm{Au}-\mathrm{ZnO}$ catalyst toward complete mineralization of MO. In addition, comparison of the $\mathrm{MO}$ decolorization and degradation in the presence of $\mathrm{ZnO}$ and $\mathrm{Au}-\mathrm{ZnO}$ confirms the higher catalytic effect of $\mathrm{Au}-\mathrm{ZnO}$ multipod catalyst against $\mathrm{ZnO}$ with the same morphology.

It is very important to explain why $\mathrm{Au}-\mathrm{ZnO}$ multipods display better photocatalytic activities than the bare $\mathrm{ZnO}$. In a typical photocatalytic process, $\mathrm{ZnO}$ multipods act as electron and hole sources. The electron-hole pairs (EHP) of $\mathrm{ZnO}$ are generated by UV excitation. The electrons on the conduction band (CB) relax to the defect level and then react with the $\mathrm{O} 2$ electron acceptors to form the superoxide anion radicals $\mathrm{O}_{2}^{--}$, and the holes in the valence band (VB) 

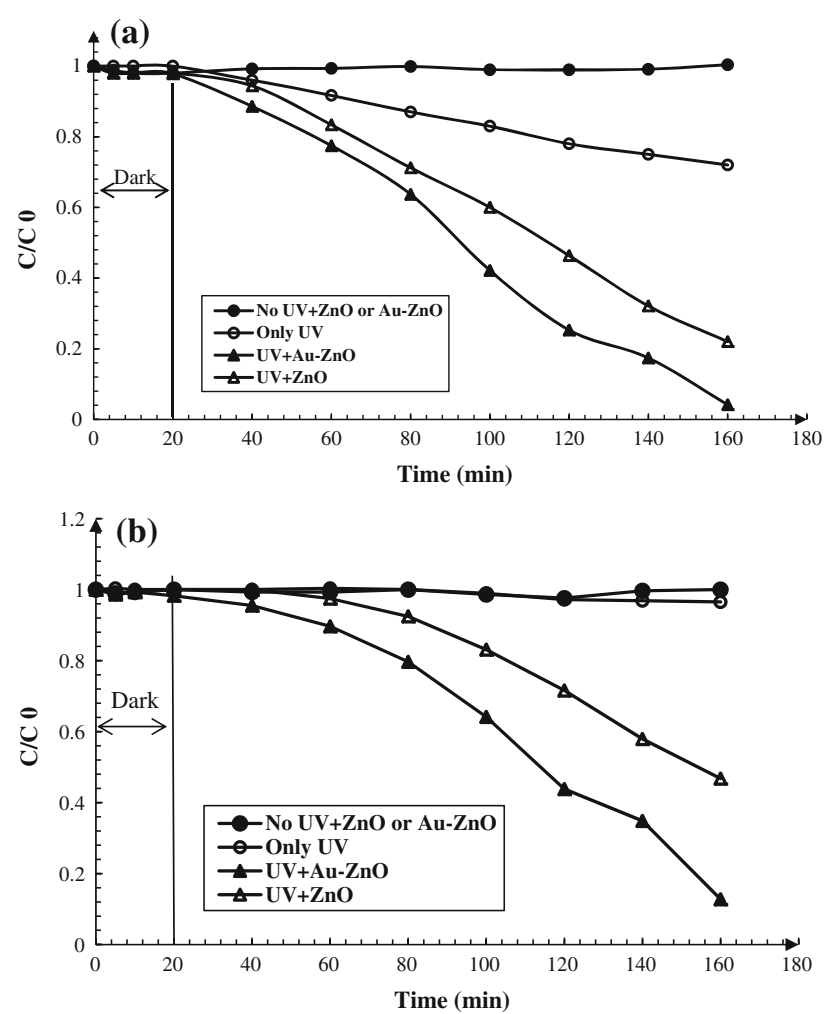

Fig. 6 Decolorization (a) and degradation (b) rates of MO. Conditions: $100 \mathrm{~mL} \mathrm{MO}$ solution with the concentration of $10.0 \mathrm{mg} \mathrm{L}^{-1}$; $\mathrm{Au}-\mathrm{ZnO}, 10.0 \mathrm{mg}$ and $\mathrm{pH} 6.5$

react with water to form hydroxyl anion radicals (Lin et al. 2005). However, EHP recombination reduces the formation of $\mathrm{O}_{2}^{--}$and thus the photocatalytic activity (Goto et al. 2004). Au-NPs act as sinks of photo-generated electrons and induce a shift of the Fermi level toward more negative potentials (Subramanian et al. 2003). The Au-ZnO interface can transfer electrons from $\mathrm{ZnO}$ to $\mathrm{Au}$ by a charge equilibration process and lower EHP recombination to enhance the photocatalytic activity.

Optimization of photocatalytic conditions

In the optimization procedure, the efficiency percentage $(E \%)$ for the degradation and decolorization processes was used to monitor the photocatalytic activity. E\% was calculated as follows:

$E(\%)=\frac{C_{0}-C_{t}}{C_{0}} \times 100$

where $C_{0}$ is the concentration of $\mathrm{MO}$ after adsorptiondesorption equilibrium at dark $(t=0)$ and $C_{t}$ is the remaining concentration of $\mathrm{MO}$ at the reaction time, $t$ (min). Concentration of the MO dye in the solution was determined by measuring the absorbance intensities at
$464 \mathrm{~nm}$ (for decolorization) and $272 \mathrm{~nm}$ (for degradation) and with the use of calibration curves. All experiments were conducted in triplicates and the mean value of the results was used.

\section{Effect of $p H$}

The solution $\mathrm{pH}$ is an important operational parameter, which plays a significant role in the photocatalytic process of various pollutants. Effect of $\mathrm{pH}$ on the photodegradation of MO was studied at the $\mathrm{pH}$ range of 3.0-8.0. More acidic $(\mathrm{pH}<3.0)$ values were not studied due to the dissolution of $\mathrm{ZnO}$ at low $\mathrm{pH}$ values. The $\mathrm{pH}$ of the solution was adjusted before irradiation by the addition of nitric acid or sodium hydroxide, and it was not controlled during the course of the reaction. The results showed that the degradation and decolorization efficiencies increase with the increase in the $\mathrm{pH}$ values up to 6.5 and then decrease at higher $\mathrm{pH}$ values. Thus, the $\mathrm{pH}$ value of 6.5 was selected as the optimal solution $\mathrm{pH}$ for the further photocatalytic experiments.

Surface charge is formed on a metal oxide as a result of ionization and complexation reaction of surface hydroxyl groups. Surface charge density as a function of $\mathrm{pH}$ is a very important characteristic of the surface properties of the metal oxide/solution. Thus, $\mathrm{pH}$ of the point of zero charge $\left(\mathrm{pH}_{\mathrm{pzc}}\right)$ depends on the alkali-acid character of surface hydroxyl groups. For $\mathrm{ZnO}$, the value of this parameter is within a very wide range, 6.9-9.8 (Sedlak and Janusz 2008). Thus, $\mathrm{ZnO}$ surface is presumably positively charged in an acidic solution $\left(\mathrm{pH}<\mathrm{pH}_{\mathrm{pzc}}\right)$ and negatively charged in an alkaline solution. On the other hand, the negatively charged form of MO $\left(p K_{a}=4\right)$ increases with increase in $\mathrm{pH}$. Due to the electrostatic attraction, by increasing the solution $\mathrm{pH}$, adsorption of the $\mathrm{MO}$ dye onto the $\mathrm{ZnO}$ surface increases, and the degradation efficiency of $\mathrm{MO}$ increases accordingly. Moreover, at a high $\mathrm{pH}$ value, concentration of the hydroxyl ions is in excess, and the $\mathrm{OH}^{-}$ions compete with the dye in the adsorption onto the surface of $\mathrm{ZnO}$, which will reduce the surface area available for dye adsorption.

\section{Effect of $\mathrm{Au}-\mathrm{ZnO}$ amount}

Effect of the amount of $\mathrm{Au}-\mathrm{ZnO}$ on the photocatalytic degradation and decolorization of $\mathrm{MO}$ was investigated at a fixed concentration of $\mathrm{MO}\left(10.0 \mathrm{mg} \mathrm{L}^{-1}\right)$ in aqueous solutions with the $\mathrm{pH}$ value of 6.5 . The data obtained showed that $E \%$ values increase with the increase in the amount of catalyst up to about $0.10 \mathrm{~g} \mathrm{~L}^{-1}$ (100\% decolorization and $94.9 \%$ degradation after $140 \mathrm{~min}$ UV 

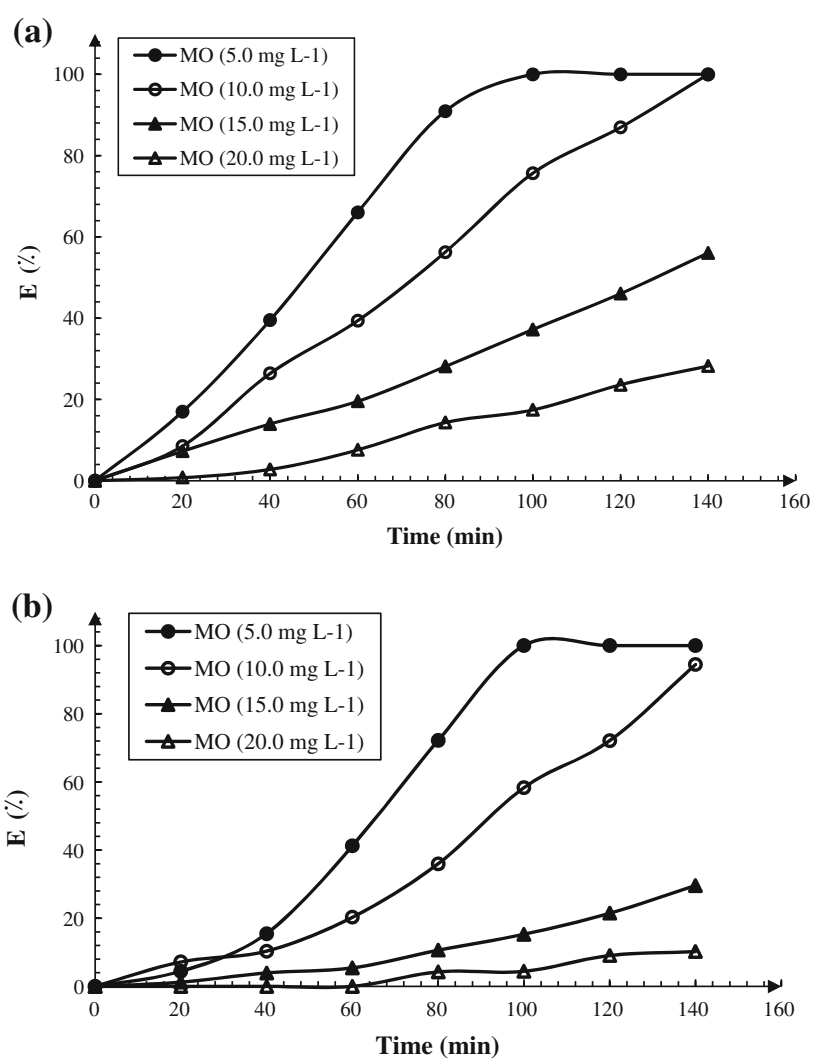

Fig. 7 Effect of the initial concentration of $\mathrm{MO}$ on the a decolorization and $\mathbf{b}$ degradation efficiencies. Conditions: $100 \mathrm{~mL}$ MO solution; $\mathrm{Au}-\mathrm{ZnO}, 10.0 \mathrm{mg}$ and $\mathrm{pH} 6.5$

irradiation) and then decrease marginally with further increase in the amount of the catalyst. Increase in the $E \%$ values with increase in the amount of catalyst can be rationalized in terms of the availability of active sites on the $\mathrm{Au}-\mathrm{ZnO}$ surface, and also the number of dye molecules adsorbed (Sun et al. 2006; Kaur and Singh 2007). However, increase in the amount of catalyst further than $0.10 \mathrm{~g} \mathrm{~L}^{-1}$ has a little negative effect on the decolorization or degradation of MO. This is due to the enhancement of light reflectance and light blocking by excessive catalyst and decrease in light penetration. Therefore, $0.10 \mathrm{~g} \mathrm{~L}^{-1}$ of catalyst was used in the next studies.

\section{Effect of the initial dye concentration}

From the application view point, it is important to study the dependence of the photocatalytic reaction on the dye concentration. The effect of initial dye concentration on the photocatalytic degradation and decolorization was investigated in the concentration range of $5.0-20 \mathrm{mg} \mathrm{L}^{-1}$. These studies were carried out in the presence of $0.1 \mathrm{~g} \mathrm{~L}^{-1}$ of the catalyst at the $\mathrm{pH}$ value of 6.5 . As shown in Fig. 7, E\% values for both degradation and decolorization decrease with the increase in the initial MO dye concentration. This is due to the fact that at a high dye concentration, the dye molecules may absorb a significant amount of light, the light absorbed by the catalyst decreases, and the catalytic efficiency reduces accordingly.

\section{Effect of dissolved oxygen}

In order to investigate the effect of dissolved $\mathrm{O}_{2}$ on the photocatalytic degradation/decolorization of $\mathrm{MO}$, the photocatalytic activities were measured under the air and pure $\mathrm{N}_{2}$ atmospheres, taking $10.0 \mathrm{mg} \mathrm{L}^{-1}$ of $\mathrm{MO}$ solution and $0.1 \mathrm{~g} \mathrm{~L}^{-1}$ of the catalyst at the $\mathrm{pH}$ value of 6.5 . In the experiments carried out under the $\mathrm{N}_{2}$ atmosphere, the suspension was purged with highly pure $\mathrm{N}_{2}$ at dark for 30 min to remove the $\mathrm{O}_{2}$ adsorbed on $\mathrm{Au}-\mathrm{ZnO}$ and $\mathrm{O}_{2}$ dissolved in the dye solution, and then the photoreaction of MO was started by turning on the UV lamp, while purging of $\mathrm{N}_{2}$ was continued. In the presence of $\mathrm{O}_{2}$, the degradation and decolorization efficiencies were $100 \%$ and $95.1 \%$, respectively. On the other hand, in the flow of highly pure $\mathrm{N}_{2}$ under UV irradiation, MO cannot be photodegraded (only $5.2 \%$ after $140 \mathrm{~min}$ ). However, a slight decolorization (19.9\% after $140 \mathrm{~min}$ ) was observed almost like the one observed in the absence of the catalyst but with UV irradiation (Fig. 6a). These results confirm that $\mathrm{O}_{2}$ is a requirement for the photocatalytic degradation process.

Reuse of $\mathrm{Au}-\mathrm{ZnO}$ catalyst

The possibility of reusing the photocatalyst was examined to see the cost-effectiveness of the method. For this purpose, the recycled experiments were performed for the photodegradation of MO under UV irradiation. After each degradation experiment, the catalyst was separated from the dye solution by centrifugation, thoroughly washed with distilled water and ethanol, and then reused for the next degradation. As shown in Table 1, the $\mathrm{Au}-\mathrm{ZnO}$ photocatalyst exhibits satisfactory photostability, and after it was recycled for three times, its photocatalytic efficiency was nearly constant.

\section{Interference study}

Since different constituents are present in wastewater, a basic understanding of the effect of foreign species on the performance of photocatalytic systems is important to ensure the operational stability of a catalyst in the photocatalytic water purification process. Thus, the influence of 
Table 1 Results obtained for repeated use of $\mathrm{Au}-\mathrm{ZnO}$ after cyclic regeneration

\begin{tabular}{lll}
\hline No. of used cycle & \multicolumn{2}{l}{$E(\%)$} \\
\cline { 2 - 3 } & Decolorization & Degradation \\
\hline 1 & 100.0 & 95.0 \\
2 & 100.0 & 93.7 \\
3 & 100.0 & 91.3 \\
4 & 87.1 & 63.2 \\
5 & 81.2 & 58.8 \\
6 & 73.4 & 56.6 \\
\hline
\end{tabular}

Table 2 Interference study results for the decolorization and degradation of $10.0 \mathrm{mg} \mathrm{L}^{-1} \mathrm{MO}$ solution

\begin{tabular}{llc}
\hline Species & \multicolumn{2}{l}{$\begin{array}{l}\text { Tolerable concentration } \\
\left(\mathrm{mg} \mathrm{L}^{-1}\right)\end{array}$} \\
\cline { 2 - 3 } & Decolorization & Degradation \\
\hline $\mathrm{SO}_{4}{ }^{2-}, \mathrm{NO}_{3}{ }^{-}, \mathrm{HCO}_{3}{ }^{-}, \mathrm{CH}_{3} \mathrm{CH}_{2} \mathrm{OH}$, & $1,000^{\mathrm{a}}$ & $1,000^{\mathrm{a}}$ \\
$\mathrm{CH}_{3} \mathrm{COOH}, \mathrm{Na}^{+}$ & & \\
$\mathrm{Cl}^{-}$ & 200 & 200 \\
$\mathrm{HPO}_{4}{ }^{2-}$ & 500 & 100 \\
$\mathrm{Mg}^{2+}, \mathrm{Ca}^{2+}$ & 100 & 40 \\
\hline
\end{tabular}

${ }^{a}$ Maximum concentration tested

most common co-exiting species on the degradation/ decolorization of MO solution was investigated under the optimum conditions. The degradation/decolorization efficiencies of the aqueous solutions containing $10.0 \mathrm{mg} \mathrm{L}^{-1}$ of $\mathrm{MO}$ and various amounts of foreign ions were measured under UV irradiation for $2 \mathrm{~h}$. The tolerance limit was defined as the concentration, which gave a change of $3 \mathrm{~S}$ (S is the standard deviation of five replicate degradation/ decolorization efficiency measurements for $10.0 \mathrm{mg} \mathrm{L}^{-1}$ of MO) in the photocatalytic efficiency. The experimental results are shown in Table 2. These results show that the common ions (even at high concentrations) in water and wastewater samples do not have any considerable interference effect on the photocatalytic activity of proposed $\mathrm{Au}-\mathrm{ZnO}$ catalyst and the catalyst could be used for the photodegradation of MO in wastewaters without significant matrix effects.

\section{Kinetic study}

Investigation of kinetics of dye decolorization is often confusing because the process is complex. It is often believed that degradation and decolorization mechanism is depends on the surface coverage of catalyst $(\theta)$. If the dye concentration is very low $(\theta \ll 1)$, the rate equation is rendered into the first-order kinetic. On the other hand, at relatively higher dye concentration $(\theta \approx 1)$, the mechanism follows the zero-order kinetics. In order to investigate kinetics of the present study, the time dependence of the MO concentration was investigated at different initial MO concentration. The MO concentration range of 5.0-20.0 mg L ${ }^{-1}$ and a constant catalyst amount $\left(0.10 \mathrm{~g} \mathrm{~L}^{-1}\right)$ were used for this study, and the data were compared for first-order and zero-order kinetics. A plot of $[\mathrm{MO}]_{t}$ versus irradiation time $(t)$ thus should give an exponential curve if the reaction mechanism follows firstorder kinetics, and if the mechanism is zero-order kinetics, the plot should be a straight line. In our case, we found straight lines $\left(R^{2} ; 0.9102-0.9989\right)$ when $[\mathrm{MO}]_{t}$ was plotted against irradiation time $(t)$. Probably, this concentration range is sufficient to form monolayer coverage $(\theta \approx 1)$ over $\mathrm{Au}-\mathrm{ZnO}$ surface, and thus, it can be concluded that under our experimental condition, MO decolorization/ degradation process manifested zero-order kinetics. From the slope of zero-order kinetics curves, the apparent rate constants of $1.2( \pm 0.2) \times 10^{-7}$ and $2.3( \pm 0.2) \times 10^{-7}$ mol L ${ }^{-1} \mathrm{~s}^{-1}$ were calculated for the degradation and decolorization of MO, respectively.

Application of catalyst in synthetic wastewater

In order to examine the performance of the $\mathrm{Au}-\mathrm{ZnO}$ catalyst in the water purification process, the proposed conditions were applied for the photodegradation of MO in untreated tap water spiked with MO. The results obtained showed that after 140 min UV irradiation, MO completely decolorized (100\%) and degraded (93.9\%) in synthetic wastewater. The data obtained reveal the capability of the $\mathrm{Au}-\mathrm{ZnO}$ photocatalyst for the degradation/decolorization of MO in synthetic wastewater samples.

\section{Conclusion}

$\mathrm{Au}-\mathrm{ZnO}$ nanostructure with well-defined multipods morphology and particle average size of $28 \mathrm{~nm}$ was prepared by a simple procedure. The $\mathrm{Au}-\mathrm{ZnO}$ catalyst was used effectively for the MO degradation and decolorization under UV irradiation. It was found that the photocatalytic activity of the catalyst was relatively higher in neutral $\mathrm{pH}$ with the small catalyst amount of $0.10 \mathrm{~g} \mathrm{~L}^{-1}$. The recycle and reuse of the catalyst were examined, and the results 
showed that the catalyst could be used three times without any change in the photocatalytic efficiency. The results obtained confirm the performance of the catalyst in the synthetic wastewater purification.

Acknowledgments The authors are thankful to the Research Council of Shahrood University of Technology for the support of this work.

\section{References}

Akyol A, Yatmaz HC, Bayramoglu M (2004) Photocatalytic decolorization of Remazol Red RR in aqueous $\mathrm{ZnO}$ suspensions. Appl Catal B 54(1):19-24. doi:10.1016/j.apcatb.2004.05.021

Cheng B, Samulski ET (2004) Hydrothermal synthesis of onedimensional $\mathrm{ZnO}$ nanostructures with different aspect ratios. Chem Commun 8:986-987. doi:10.1039/B316435G

Daneshvar N, Salari D, Khataee AR (2004) Photocatalytic degradation of azo dye acid red 14 in water on $\mathrm{ZnO}$ as an alternative catalyst to $\mathrm{TiO} 2$. J Photochem Photobiol A Chem 162(2-3): 317-322. doi:10.1016/s1010-6030(03)00378-2

Divya N, Bansal A, Jana A (2013) Photocatalytic degradation of azo dye Orange II in aqueous solutions using copper-impregnated titania. Int J Environ Sci Technol 10:1265-1274. doi:10.1007/ s13762-013-0238-8

Goto H, Hanada Y, Ohno T, Matsumura M (2004) Quantitative analysis of superoxide ion and hydrogen peroxide produced from molecular oxygen on photoirradiated $\mathrm{TiO} 2$ particles. J Catal 225(1):223-229. doi:10.1016/j.jcat.2004.04.001

Hammami S, Bellakhal N, Oturan N, Oturan MA, Dachraoui M (2008) Degradation of Acid Orange 7 by electrochemically generated \& $\mathrm{OH}$ radicals in acidic aqueous medium using a boron-doped diamond or platinum anode: a mechanistic study. Chemosphere 73(5):678-684. doi:10.1016/j.chemosphere.2008. 07.010

Hazrati N, Abdouss M, Vahid A (2014) Removal of H2S from crude oil via stripping followed by adsorption using $\mathrm{ZnO} / \mathrm{MCM}-41$ and optimization of parameters. Int $\mathbf{J}$ Environ Sci Technol 11:997-1006. doi:10.1007/s13762-013-0465-Z

He JH, Lao CS, Chen LJ, Davidovic D, Wang ZL (2005) Large-scale Ni-doped $\mathrm{ZnO}$ nanowire arrays and electrical and optical properties. J Am Chem Soc 127(47):16376-16377. doi:10. $1021 / \mathrm{ja} 0559193$

Height MJ, Pratsinis SE, Mekasuwandumrong O, Praserthdam P (2006) Ag-ZnO catalysts for UV-photodegradation of methylene blue. Appl Catal B 63(3-4):305-312. doi:10.1016/j.apcatb.2005. 10.018

Joshi RK, Hu Q, Alvi F, Joshi N, Kumar A (2009) Au decorated zinc oxide nanowires for $\mathrm{CO}$ sensing. J Phys Chem C 113(36):16199-16202. doi:10.1021/jp906458b

Kaur S, Singh V (2007) TiO2 mediated photocatalytic degradation studies of Reactive Red 198 by UV irradiation. J Hazard Mater 141(1):230-236. doi:10.1016/j.jhazmat.2006.06.123

Kavitha R, Meghani S, Jayaram V (2007) Synthesis of titania films by combustion flame spray pyrolysis technique and its characterization for photocatalysis. J Mater Sci Eng B 139(2-3):134-140. doi:10.1016/j.mseb.2007.01.040

Krishnan D, Pradeep T (2009) Precursor-controlled synthesis of hierarchical $\mathrm{ZnO}$ nanostructures, using oligoaniline-coated $\mathrm{Au}$ nanoparticle seeds. J Cryst Growth 311(15):3889-3897. doi:10. 1016/j.jcrysgro.2009.06.019
Li D, Haneda H (2003) Morphologies of zinc oxide particles and their effects on photocatalysis. Chemosphere 51(2):129-137. doi:10. 1016/s0045-6535(02)00787-7

Li FB, Li XZ (2002) The enhancement of photodegradation efficiency using Pt-TiO2 catalyst. Chemosphere 48(10):1103-1111. doi:10.1016/s0045-6535(02)00201-1

Lin H-F, Liao S-C, Hung S-W (2005) The dc thermal plasma synthesis of $\mathrm{ZnO}$ nanoparticles for visible-light photocatalyst. J Photochem Photobiol, A 174(1):82-87. doi:10.1016/j. jphotochem.2005.02.015

Liqiang J, Dejun W, Baiqi W, Shudan L, Baifu X, Honggang F, Jiazhong S (2006) Effects of noble metal modification on surface oxygen composition, charge separation and photocatalytic activity of $\mathrm{ZnO}$ nanoparticles. J Mol Catal A: Chem 244(1-2):193-200. doi:10.1016/j.molcata.2005.09.020

Liu J, Huang X, Li Y, Duan J, Ai H (2006) Large-scale synthesis of flower-like $\mathrm{ZnO}$ structures by a surfactant-free and low-temperature process. Mater Chem Phys 98(2-3):523-527. doi:10.1016/ j.matchemphys.2005.09.075

Melgoza D, Hernandez-Ramirez A, Peralta-Hernandez JM (2009) Comparative efficiencies of the decolourisation of Methylene Blue using Fenton's and photo-Fenton's reactions. Photochem Photobiol Sci 8(5):596-599. doi:10.1039/B817287K

Pawinrat P, Mekasuwandumrong O, Panpranot J (2009) Synthesis of $\mathrm{Au}-\mathrm{ZnO}$ and $\mathrm{Pt}-\mathrm{ZnO}$ nanocomposites by one-step flame spray pyrolysis and its application for photocatalytic degradation of dyes. Catal Commun 10(10):1380-1385. doi:10.1016/j.catcom. 2009.03.002

Pirkanniemi K, Sillanpää M (2002) Heterogeneous water phase catalysis as an environmental application: a review. Chemosphere 48(10):1047-1060. doi:10.1016/s0045-6535(02)00 168-6

Robinson T, McMullan G, Marchant R, Nigam P (2001) Remediation of dyes in textile effluent: a critical review on current treatment technologies with a proposed alternative. Bioresour Technol 77(3):247-255. doi:10.1016/s0960-8524(00)00080-8

Sajanlal PR, Sreeprasad TS, Nair AS, Pradeep T (2008) Wires, plates, flowers, needles, and core-shells: diverse nanostructures of gold using polyaniline templates. Langmuir 24(9):4607-4614. doi:10. 1021/la703593c

Sedlak A, Janusz W (2008) Specific adsorption of carbonate ions at the zinc oxide/electrolyte solution interface. Physicochem Probl Miner Process 42(1):57-66

Subramanian V, Wolf EE, Kamat PV (2003) Green emission to probe photoinduced charging events in $\mathrm{ZnO}-\mathrm{Au}$ nanoparticles: charge distribution and fermi-level equilibration $\dagger$. J Phys Chem B 107(30):7479-7485. doi:10.1021/jp0275037

Sun J, Wang X, Sun J, Sun R, Sun S, Qiao L (2006) Photocatalytic degradation and kinetics of Orange G using nano-sized Sn(IV)/ TiO2/AC photocatalyst. J Mol Catal A: Chem 260(1-2):241-246. doi:10.1016/j.molcata.2006.07.033

Sun J-H, Dong S-Y, Wang Y-K, Sun S-P (2009) Preparation and photocatalytic property of a novel dumbbell-shaped $\mathrm{ZnO}$ microcrystal photocatalyst. J Hazard Mater 172(2-3):1520-1526. doi:10.1016/j.jhazmat.2009.08.022

Sun L, Zhao D, Song Z, Shan C, Zhang Z, Li B, Shen D (2011) Gold nanoparticles modified $\mathrm{ZnO}$ nanorods with improved photocatalytic activity. J Colloid Interface Sci 363(1):175-181. doi:10. 1016/j.jcis.2011.07.005

Szabó-Bárdos E, Czili H, Horváth A (2003) Photocatalytic oxidation of oxalic acid enhanced by silver deposition on a $\mathrm{TiO} 2$ surface. J Photochem Photobiol, A 154(2-3):195-201. doi:10.1016/ s1010-6030(02)00330-1

Tao J, Chen X, Sun Y, Shen Y, Dai N (2008) Controllable preparation of $\mathrm{ZnO}$ hollow microspheres by self-assembled block 
copolymer. Colloids Surf A 330(1):67-71. doi:10.1016/j. colsurfa.2008.07.035

Wang Z, X-f Qian, Yin J, Z-k Zhu (2004) Large-scale fabrication of tower-like, flower-like, and tube-like $\mathrm{ZnO}$ arrays by a simple chemical solution route. Langmuir 20(8):3441-3448. doi:10. 1021/la036098n

Wang N, Sun C, Zhao Y, Zhou S, Chen P, Jiang L (2008) Fabrication of three-dimensional $\mathrm{ZnO} / \mathrm{TiO} 2$ heteroarchitectures via a solution process. J Mater Chem 18(33):3909-3911

Wu J-J, Tseng C-H (2006) Photocatalytic properties of nc-Au/ZnO nanorod composites. Appl Catal B 66(1-2):51-57. doi:10.1016/j. apcatb.2006.02.013
Xie J, Li Y, Zhao W, Bian L, Wei Y (2011) Simple fabrication and photocatalytic activity of $\mathrm{ZnO}$ particles with different morphologies. Powder Technol 207(1-3):140-144. doi:10.1016/j. powtec.2010.10.019

Zheng Y, Yu X, Xu X, Jin D, Yue L (2010) Preparation of ZnO particle with novel nut-like morphology by ultrasonic pretreatment and its luminescence property. Ultrason Sonochem 17(1):7-10. doi:10.1016/j.ultsonch.2009.06.010 